\title{
Blood pressure variability in individuals with and without (pre)diabetes
}

Citation for published version (APA):

Zhou, T. L., Reesink, K., Schram, M., Koster, A., Schaper, N., Dagnelie, P., van der Kallen, C., Sep, S., Stehouwer, C., \& Henry, R. (2018). Blood pressure variability in individuals with and without (pre)diabetes: the Maastricht Study. Journal of Hypertension, 36(2), 259-267.

https://doi.org/10.1097/HJH.0000000000001543

Document status and date:

Published: 01/02/2018

DOI:

10.1097/HJH.0000000000001543

Document Version:

Publisher's PDF, also known as Version of record

Document license:

Taverne

Please check the document version of this publication:

- A submitted manuscript is the version of the article upon submission and before peer-review. There can be important differences between the submitted version and the official published version of record.

People interested in the research are advised to contact the author for the final version of the publication, or visit the DOI to the publisher's website.

- The final author version and the galley proof are versions of the publication after peer review.

- The final published version features the final layout of the paper including the volume, issue and page numbers.

Link to publication

\footnotetext{
General rights rights.

- You may freely distribute the URL identifying the publication in the public portal. please follow below link for the End User Agreement:

www.umlib.nl/taverne-license

Take down policy

If you believe that this document breaches copyright please contact us at:

repository@maastrichtuniversity.nl

providing details and we will investigate your claim.
}

Copyright and moral rights for the publications made accessible in the public portal are retained by the authors and/or other copyright owners and it is a condition of accessing publications that users recognise and abide by the legal requirements associated with these

- Users may download and print one copy of any publication from the public portal for the purpose of private study or research.

- You may not further distribute the material or use it for any profit-making activity or commercial gain

If the publication is distributed under the terms of Article $25 \mathrm{fa}$ of the Dutch Copyright Act, indicated by the "Taverne" license above, 


\title{
Original Article
}

\section{Blood pressure variability in individuals with and without (pre)diabetes: The Maastricht Study}

\author{
Tan Lai Zhou ${ }^{a, b}$, Abraham A. Kroon ${ }^{a, b}$, Koen D. Reesink ${ }^{b, c}$, Miranda T. Schram ${ }^{a, b, d}$ \\ Annemarie Koster ${ }^{e, f}$, Nicolaas C. Schaper ${ }^{a, b, f}$, Pieter C. Dagnelie ${ }^{b, f, g}$, Carla J.H. van der Kallen ${ }^{a, b}$, \\ Simone J.S. Sep ${ }^{a, b}$, Coen D.A. Stehouwer ${ }^{a, b}$, and Ronald M.A. Henry ${ }^{a, b, d}$
}

Objective: The mechanisms associating (pre)diabetes and cardiovascular disease (CVD) are incompletely understood. We hypothesize that greater blood pressure variability (BPV) may underlie this association, due to its association with (incident) CVD. Therefore, we investigated the association between (pre)diabetes and very short-term to mid-term BPV, that is within-visit, 24-h and 7-day BPV.

Methods: Cross-sectional data from The Maastricht Study [normal glucose metabolism (NGM), $n=1924$; prediabetes, $n=511$; type 2 diabetes mellitus (T2DM), $n=975 ; 51 \%$ men, aged $60 \pm 8$ years]. We determined SD for withinvisit BPV $(n=3244)$, average real variability for $24-h$ BPV ( $n=2699)$ day (0900-2100 h) and night (0100-0600 h) separately, and SD for 7-day BPV $(n=2259)$. Differences in BPV as compared with NGM were assessed by multiple linear regressions with adjustment for potential confounders.

Results: In T2DM, the average systolic/diastolic values of within-visit, 24-h and 7-day BPV were 4.8/2.6, 10.5/7.3 and $10.4 / 6.5 \mathrm{mmHg}$, respectively, and in prediabetes 4.9 / 2.6, $10.3 / 7.0$ and $9.4 / 5.9 \mathrm{mmHg}$, respectively. T2DM was associated with greater nocturnal systolic BPV [0.42 $\mathrm{mmHg}$ (95\% confidence interval: 0.05-0.80)], and greater 7-day systolic $[0.76 \mathrm{mmHg}(0.32-1.19)]$ and diastolic BPV [0.65 mmHg (0.29-1.01)], whereas prediabetes was associated with greater within-visit systolic BPV only [0.35 mmHg (0.06-0.65)], as compared with NGM.

Conclusion: Both T2DM and prediabetes are associated with slightly greater very short-term to mid-term BPV, which may, according to previous literature, explain a small part of the increased CVD risk seen in (pre)diabetes. Nevertheless, these findings do not detract from the fact that very short-term to mid-term BPV is substantial and important in individuals with and without (pre)diabetes.

Keywords: average real variability, blood pressure variability, cardiovascular diseases, diabetes mellitus, prediabetic state

Abbreviations: BPV, blood pressure variability; CKD-EPI, Chronic Kidney Disease Epidemiology Collaboration; eGFR, estimated glomerular filtration rate; HDL-C, HDL cholesterol; LDL-C, LDL cholesterol; NGM, normal glucose metabolism; T2DM, type 2 diabetes mellitus

\section{INTRODUGTION}

$\mathrm{T}$ he mechanisms underlying the associations between type 2 diabetes (T2DM) and cardiovascular disease (CVD) are still only partially understood [1]. Importantly, the pathways linking T2DM to CVD are thought to be already present, to a somewhat lesser extent, in prediabetes [2]. A better understanding of these mechanisms is crucial, as it has been projected that, in 2025, 600 million individuals will suffer from T2DM, which will be followed by an epidemic of CVD [3].

Blood pressure (BP) variability (BPV), that is greater fluctuations of SBP or DBP at given mean pressures, has been shown to be associated with incident CVD independent of mean pressures [4] and thus may play a role in the association between (pre)diabetes and CVD. However, BPV in individuals with (pre)diabetes has not been systematically investigated, as previous studies have been relatively small [5-7], have targeted selected study populations [8,9], have used nonstandardized BP measurements [8,9] and/or have not adequately adjusted for the use of the various classes of antihypertensive medication [5-9], which may increase or decrease BPV depending on their therapeutic mechanism of action $[10,11]$. In addition, BPV in individuals with (pre)diabetes has not been systematically compared with that in individuals with normal glucose metabolism (NGM). The latter is important, because BP regulation in individuals with (pre)diabetes is known to differ from that in individuals with NGM in many ways [12], and these differences may increase BPV [13]. We therefore hypothesized that BPV may be greater in individuals with (pre)diabetes. Indeed, there is some evidence that this may be the case [5-9].

\footnotetext{
Journal of Hypertension 2018, 36:259-267

aDepartment of Internal Medicine, Maastricht University Medical Centre+, ${ }^{\mathrm{b} C}$ Cardiovascular Research Institute Maastricht (CARIM), 'Department of Biomedical Engineering, Maastricht University, ${ }^{d}$ Heart and Vascular Centre, Maastricht University Medical Centre+, ${ }^{e}$ Department of Social Medicine, ${ }^{f}$ Care and Public Health Research Institute (CAPHRI) and ${ }^{9}$ Department of Epidemiology, Maastricht University, Maastricht, The Netherlands

Correspondence to Ronald M.A. Henry, Department of Internal Medicine, Maastricht University Medical Centre+, P. Debyelaan 25, PO Box 5800, 6202 AZ Maastricht, The Netherlands. Tel: +314338715 62; fax: +314338750 06;

e-mail: rma.henry@mumc.nl

Received 23 May 2017 Revised 28 July 2017 Accepted 3 August 2017

J Hypertens 36:259-267 Copyright (C) 2018 Wolters Kluwer Health, Inc. All rights reserved.

DOI:10.1097/HJH.0000000000001543
} 
In view of the above, we investigated very short-term to mid-term (i.e. within-visit, 24-h and 7-day) BPV in participants of The Maastricht Study, a large population-based cohort study in which individuals with T2DM have been oversampled [14].

\section{METHODS}

\section{Study design and population}

We used data from The Maastricht Study, an observational prospective population-based cohort study. The rationale and methodology have been described previously [14]. In brief, the study focuses on the cause, pathophysiology, complications and comorbidities of T2DM and is characterized by an extensive phenotyping approach. Eligible for participation were all individuals aged between 40 and 75 years and living in the southern part of the Netherlands. Participants were recruited through mass media campaigns and from the municipal registries and the regional Diabetes Patient Registry via mailings. Recruitment was stratified according to known T2DM status, with an oversampling of individuals with T2DM, for reasons of efficiency. The current report includes cross-sectional data from the first 3451 participants, who completed the baseline survey between November 2010 and September 2013. The examinations of each participant were performed within a time window of 3 months. The study has been approved by the institutional medical ethical committee (NL31329.068.10) and the Minister of Health, Welfare and Sports of the Netherlands (Permit 131088-105234-PG). All participants gave written informed consent.

\section{Data collection}

\section{Blood pressure measurements and determination of blood pressure variability}

Within-visit BPV was derived from office BP measurements according to international standards [15]. In short, office BP measurements were performed with the use of an oscillometric device (705-IT; Omron Healthcare, Kyoto, Japan), in a seated position on the right arm by trained research assistants, after $10 \mathrm{~min}$ of rest. BP was measured three times consecutively, with a 1-min interval. BP readings were taken between 09:30 and 11:30 a.m. as part of the first investigational study visit [14]. Within-visit BPV was computed as the $\mathrm{SD}$ when at least two BP readings were available.

Twenty-four-hour BPV was derived from ambulatory BP measurements according to international standards [16]. In short, ambulatory BP measurements were performed with the use of an oscillometric device (WatchBP O3; Microlife, Widnau, Switzerland) on the nondominant arm. Between 0800 and $2300 \mathrm{~h}$ readings were taken every $15 \mathrm{~min}$; between 2300 and $0800 \mathrm{~h}$, the interval was set at $30 \mathrm{~min}$. Average real variability was calculated as measurement of 24-h BPV. The average real variability is the sum of the absolute differences of consecutive BP measurements divided by the number of differences and therefore takes into account the time series variability [17]. The 24-h BPV was calculated when at least 14 valid BP differences during daytime and at least seven valid BP differences during night-time were available. In addition, day (between
0900 and 2100 h) and night (between 0100 and $0600 \mathrm{~h}$ ) average real variability values were analyzed separately.

Seven-day BPV was derived from home BP measurements according to international standards [18]. In short, home BP measurements were performed by participants with the use of an oscillometric device (WatchBP Home; Microlife) for 7 consecutive days, after instruction by trained researchers. Participants were instructed to measure their BP after at least 5-min rest in a seated position in the morning before breakfast and in the evening after dinner on the nondominant arm. The device measured BP twice consecutively each reading, with a 1-min interval. As 7day BPV variable, SD was computed when at least $15 \mathrm{BP}$ readings were available.

\section{Glucose metabolism status}

To determine glucose metabolism status, all participants, except those who used insulin, underwent a standardized 2-h 75 g oral glucose tolerance test (OGTT) after an overnight fast. For safety reasons, participants with a fasting glucose level above $11.0 \mathrm{mmol} / \mathrm{l}$, as determined by a finger prick, did not undergo the OGTT. For these individuals, fasting glucose level and information about diabetes medication were used to determine glucose metabolism status. Glucose metabolism status was defined according to the WHO 2006 criteria into NGM, prediabetes (impaired fasting glucose and/or impaired glucose tolerance) and T2DM [19]. Participants with type 1 diabetes or other forms of diabetes were excluded.

\section{Covariates}

Alcohol consumption, smoking status, history of CVD and physical activity were assessed by questionnaire. Alcohol consumption was defined as nonconsumer, low consumer ( $\leq 7$ alcoholic drinks/week for women; $\leq 14$ alcoholic drinks/week for men) or high consumer $(>7$ alcoholic drinks/week for women; >14 alcohol drinks/week for men). Smoking status was categorized into never, former and current smoker. BMI, waist circumference, total cholesterol (TC), HDL cholesterol (HDL-C), LDL cholesterol (LDL-C), triglycerides, fasting plasma glucose, postload glucose and glycosylated hemoglobin (HbA1c) were determined as described elsewhere [14]. Estimated glomerular filtration rate (eGFR) was computed with the Chronic Kidney Disease Epidemiology Collaboration formula, using serum creatinine and cystatin C [20]. Information on the use of lipid-modifying and/or antihypertensive medication, that is generic names, doses and frequencies, were collected during an in person medication interview.

\section{Statistical analysis}

All data were analyzed using IBM SPSS software version 23.0 for Windows (IBM Corp., Somers, New York, USA). Data are presented as $n(\%)$, mean \pm SD or median [interquartile range (IQR)]. To test for baseline differences, oneway analysis of variance (with $P$ for linear trend) or the Kruskal-Wallis test for normally and nonnormally distributed continuous variables respectively, and $\chi^{2}$ test for categorical variables were used. Associations between prediabetes, T2DM and BPV (within-visit, 24-h and 7-day; systolic and diastolic) were examined with the use of multiple linear regression models. Model 1 was adjusted 
for age and sex; model 2 was additionally adjusted for mean SBP or DBP (either from office, 24-h or 7-day BP measurements, as appropriate); model 3 was additionally adjusted for smoking status and alcohol consumption; model 4 was additionally adjusted for BMI, history of CVD, HDL-C, LDL-C, use of lipid-modifying medication, eGFR; and model 5 was additionally adjusted for antihypertensive medication classes (beta-blockers, angiotensin-converting-enzyme inhibitors, angiotensin II receptor blockers, calcium channel blockers and nonloop diuretics separately). These models were repeated in a series of additional analyses for within-visit BPV with coefficient of variation and maximum-minimum difference instead of SD, for 24-h BPV with weighted SD and weighted coefficient of variation [21] instead of average real variability, and for 7-day BPV with coefficient of variation and average real variability instead of SD. Further additional analyses were done with adjustments for waist circumference (instead of $\mathrm{BMI}$ ), heart rate (HR), the actual number of $\mathrm{BP}$ measurements and physical activity as confounders. In addition, to test whether these associations were modified by sex, we used interaction terms between glucose metabolism status and sex in the fully adjusted models. A two-sided $P$ value of less than 0.05 was considered statistically significant [22], except for the interaction analyses, in which we used $P$ less than 0.10 .

\section{RESULTS}

\section{Study population}

From the 3451 participants, 41 participants with type 1 diabetes or other forms of diabetes were excluded. Data on covariates were missing for three participants on BMI, for four participants on cholesterol values, for four on medication history, for 33 on eGFR, for 63 on smoking habits, for 69 on alcohol use and for 108 on history of prior CVD (not mutually exclusive). In addition, data on BPs were missing for four participants on office BP, for 363 participants on 24-h BP and for 976 participants on 7-day home BP (not mutually exclusive). In the remaining participants, 3244 participants had adequate office BP measurement data, 2699 participants had adequate 24-h ambulatory BP measurement data and 2259 participants had adequate 7-day home BP measurement data [not mutually inclusive (Fig. 1)]. Missing data on BP measurements were due to logistic and technical reasons (e.g. measurement failures). Participants with and without missing data did not differ with regard to their baseline clinical characteristics, except for smoking [participants with missing ambulatory BP measurement data were more often current smokers (18.0 vs. $13.0 \%)$ ].

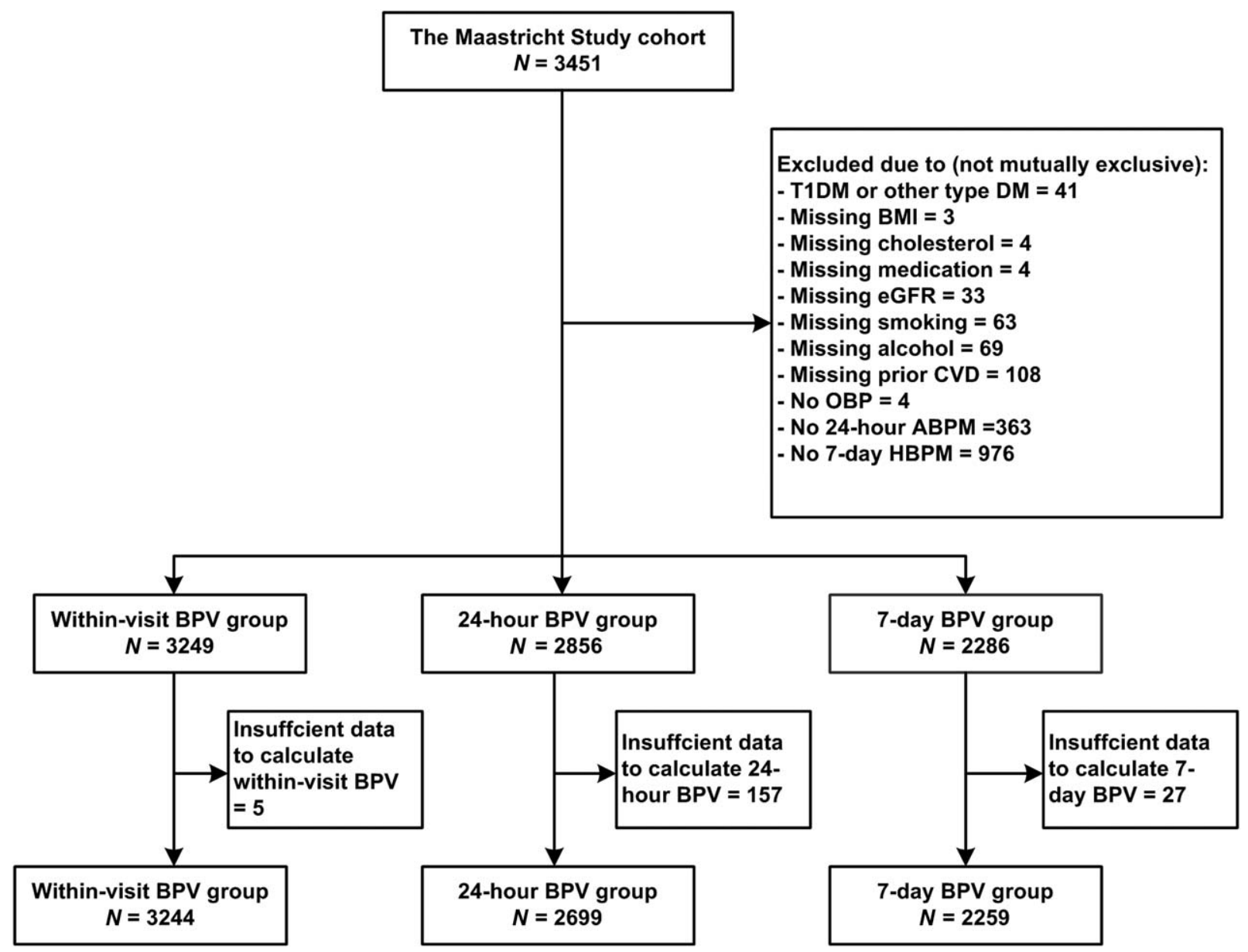

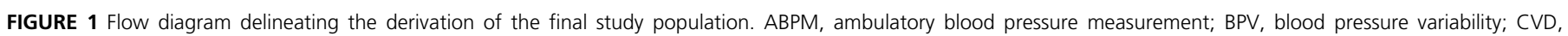

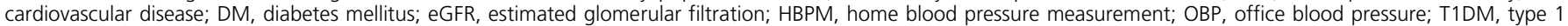
diabetes mellitus. 


\section{Characteristics of the study population}

Tables 1 and 2 show characteristics of the within-visit BPV study population categorized according to glucose metabolism status. From NGM to T2DM, age, BMI, HbA1c, prior CVD and the use of lipid-modifying medication increased ( $P$ for trend $<0.001$ ); TC and LDL-C decreased ( $P$ for trend $<0.001$ ). The use of antihypertensive medication increased ( $P$ for trend $<0.001$ ), as did values of systolic, ambulatory and home BP measurements $(P$ for trend $<0.001$ ). All calculated BPV variables, except for within-visit systolic BPV, increased from NGM to T2DM ( $P$ for trend $<0.001-0.069$ ). The characteristics of the within-visit, 24-h and 7-day BPV study populations were similar (Supplemental material Tables S1 and S2, http://links.lww.com/HJH/A838).

\section{Associations between glucose metabolism status and blood pressure variability}

\section{Within-visit blood pressure variability}

After adjustment for age, sex (model 1), mean SBP or DBP (model 2), smoking behavior and alcohol consumption (model 3), BMI, prior CVD, HDL-C, LDL-C, lipidmodifying medication, eGFR (model 4) and antihypertensive medication (model 5), only prediabetes was associated with statistically significantly greater withinvisit systolic BPV as compared with NGM [regression coefficient $(\beta)$ and $95 \%$ confidence interval]: $0.35 \mathrm{mmHg}$ (0.06-0.65), whereas T2DM was not (Table 3, upper panel).

TABLE 1. Characteristics of the within-visit blood pressure variability study population

\begin{tabular}{|c|c|c|c|c|}
\hline & NGM, $n=1838$ & Prediabetes, $n=496$ & T2DM, $n=908$ & $P(\text { trend })^{a}$ \\
\hline Age (years) & $57.9 \pm 8.2$ & $61.5 \pm 7.5$ & $62.7 \pm 7.7$ & $<0.001$ \\
\hline Men & $797(43.3 \%)$ & $270(54.4 \%)$ & $620(68.3 \%)$ & $<0.001$ \\
\hline Smoking behavior & & & & $<0.001$ \\
\hline Never & 719 (39.1\%) & $148(29.8 \%)$ & $257(28.3 \%)$ & \\
\hline Former & $887(48.2 \%)$ & $286(57.7 \%)$ & $507(55.8 \%)$ & \\
\hline Current & $233(12.7 \%)$ & $62(12.5 \%)$ & $144(15.9 \%)$ & \\
\hline Alcohol consumption & & & & $<0.001$ \\
\hline None & $249(13.5 \%)$ & $79(15.9 \%)$ & $275(30.3 \%)$ & \\
\hline Low & $1073(58.3 \%)$ & $262(52.8 \%)$ & $457(50.3 \%)$ & \\
\hline High & $517(28.1 \%)$ & $156(31.3 \%)$ & $176(19.4 \%)$ & \\
\hline History of cardiovascular disease & $219(11.9 \%)$ & $69(13.9 \%)$ & $256(28.2 \%)$ & $<0.001$ \\
\hline BMI $\left(k g / m^{2}\right)$ & $25.5 \pm 3.6$ & $27.8 \pm 4.2$ & $29.8 \pm 5.0$ & $<0.001$ \\
\hline Waist circumference $(\mathrm{cm})$ & $90.5 \pm 11.2$ & $98.3 \pm 12.4$ & $105.8 \pm 13.5$ & $<0.001$ \\
\hline MVPA (h/week) & $6.2 \pm 4.5$ & $5.1 \pm 4.1$ & $4.3 \pm 4.0$ & $<0.001$ \\
\hline Total cholesterol (mmol/l) & $5.6 \pm 1.0$ & $5.4 \pm 1.1$ & $4.4 \pm 1.0$ & $<0.001$ \\
\hline HDL cholesterol (mmol/l) & $1.7 \pm 0.5$ & $1.5 \pm 0.4$ & $1.3 \pm 0.4$ & $<0.001$ \\
\hline LDL cholesterol (mmol/l) & $3.4 \pm 0.9$ & $3.3 \pm 1.0$ & $2.4 \pm 0.9$ & $<0.001$ \\
\hline Triglycerides (mmol/l) & $1.06(0.80-1.45)$ & $1.35(1.02-1.83)$ & $1.53(1.12-2.14)$ & $<0.001$ \\
\hline eGFR $\left(\mathrm{ml} / \mathrm{min}\right.$ per $\left.1.73 \mathrm{~m}^{2}\right)$ & $90.3 \pm 13.2$ & $86.7 \pm 14.1$ & $84.7 \pm 17.1$ & $<0.001$ \\
\hline $\mathrm{HbA1c}(\mathrm{mmol} / \mathrm{mol})^{\mathrm{c}}$ & $36.0 \pm 3.7$ & $38.8 \pm 4.5$ & $52.1 \pm 11.6$ & $<0.001$ \\
\hline Fasting plasma glucose $(\mathrm{mmol} / \mathrm{l})^{\mathrm{d}}$ & $5.2 \pm 0.4$ & $5.9 \pm 0.6$ & $7.9 \pm 2.0$ & $<0.001$ \\
\hline Postload glucose $(\mathrm{mmol} / \mathrm{l})^{\mathrm{e}}$ & $5.4 \pm 1.1$ & $8.1 \pm 1.7$ & $14.3 \pm 3.8$ & $<0.001$ \\
\hline Use of antidiabetic medication & - & - & $711(78.3 \%)$ & \\
\hline Oral antidiabetics & - & - & $663(73.0 \%)$ & \\
\hline Insulin & - & - & $194(21.4 \%)$ & \\
\hline Use of lipid-modifying medication & $303(16.5 \%)$ & $175(35.3 \%)$ & $679(74.8 \%)$ & $<0.001$ \\
\hline Use of antihypertensive medication & $408(22.2 \%)$ & $224(45.2 \%)$ & $654(72.0 \%)$ & $<0.001$ \\
\hline Beta-blockers & $165(9.0 \%)$ & $105(21.2 \%)$ & $308(33.9 \%)$ & $<0.001$ \\
\hline Calcium channel blockers & $66(3.6 \%)$ & $38(7.7 \%)$ & $192(21.1 \%)$ & $<0.001$ \\
\hline ACE inhibitors & $101(5.5 \%)$ & $46(9.3 \%)$ & $238(26.2 \%)$ & $<0.001$ \\
\hline Angiotensin II receptor blockers & $177(9.6 \%)$ & $111(22.4 \%)$ & $301(33.1 \%)$ & $<0.001$ \\
\hline Diuretics & $125(6.8 \%)$ & $94(19.0 \%)$ & 305 (33.6\%) & $<0.001$ \\
\hline \multicolumn{5}{|l|}{ Blood pressure measurements } \\
\hline Mean office SBP (mmHg) & $130.7 \pm 17.2$ & $137.5 \pm 17.0$ & $142.3 \pm 18.1$ & $<0.001$ \\
\hline Mean office DBP (mmHg) & $75.2 \pm 9.9$ & $78.1 \pm 9.6$ & $77.3 \pm 9.7$ & $<0.001$ \\
\hline Mean 24-h SBP $(\mathrm{mmHg})^{f}$ & $118.7 \pm 11.2$ & $122.5 \pm 11.9$ & $123.6 \pm 12.2$ & $<0.001$ \\
\hline Mean 24-h DBP $(\mathrm{mmHg})^{f}$ & $75.3 \pm 7.2$ & $76.2 \pm 7.1$ & $74.3 \pm 7.2$ & 0.010 \\
\hline Mean home SBP $(\mathrm{mmHg})^{\mathrm{g}}$ & $124.0 \pm 12.8$ & $128.7 \pm 12.3$ & $133.5 \pm 13.4$ & $<0.001$ \\
\hline Mean home DBP $(\mathrm{mmHg})^{g}$ & $77.0 \pm 8.5$ & $78.0 \pm 7.7$ & $77.8 \pm 7.9$ & 0.029 \\
\hline
\end{tabular}

Data are presented as $n(\%)$, mean \pm SD or median (IQR). eGFR, estimated glomerular filtration rate; HbA1C, glycosylated hemoglobin; MVPA, moderate-to-vigorous physical activity; NGM, normal glucose metabolism; T2DM, type 2 diabetes mellitus.

a $P$ (Trend) for comparing linear trends across participants with normal glucose metabolism, prediabetes and T2DM were calculated with one-way ANOVA for normally distributed

variables, the Kruskal-Wallis test for nonnormally disturbed variables and the $\chi^{2}$ test for categorical variables.

${ }^{b}$ Available in 2834 participants ( $n=1647$ for NGM, $n=439$ for prediabetes, $n=748$ for T2DM)

${ }^{c}$ Available in 3231 participants ( $n=1933$ for NGM, $n=439$ for prediabetes, $n=905$ for T2DM)

${ }^{\mathrm{d}}$ Available in 3241 participants ( $n=1838$ for NGM, $n=496$ for prediabetes, $n=907$ for T2DM).

${ }^{e}$ Available in 3011 participants ( $n=1834$ for NGM, $n=494$ for prediabetes, $n=683$ for T2DM)

fValues shown for 24-h BPV study population ( $n=1535$ for NGM, $n=411$ for prediabetes, $n=753$ for T2DM).

gValues shown for 7-day BPV study population ( $n=1270$ for NGM, $n=337$ for prediabetes, $n=652$ for T2DM). 
TABLE 2. Within-visit, 24-h and 7-day blood pressure variability according to glucose metabolism status

\begin{tabular}{|c|c|c|c|c|}
\hline & NGM, $n=1839$ & Prediabetes, $n=496$ & T2DM, $n=908$ & $P$ (trend $^{\mathrm{a}}$ \\
\hline \multicolumn{5}{|l|}{ Within-visit BPV } \\
\hline $\mathrm{SD}_{\mathrm{SBP}}(\mathrm{mmHg})$ & $4.48 \pm 2.76$ & $4.93 \pm 2.98$ & $4.82 \pm 3.08$ & 0.001 \\
\hline $\mathrm{SD}_{\mathrm{DBP}}(\mathrm{mmHg})$ & $2.46 \pm 1.62$ & $2.59 \pm 1.73$ & $2.62 \pm 1.93$ & 0.013 \\
\hline 24-h BPV & $(n=1535)$ & $(n=411)$ & $(n=753)$ & \\
\hline $\mathrm{ARV}_{\mathrm{SBP}}(\mathrm{mmHg})$ & $9.73 \pm 2.37$ & $10.27 \pm 2.58$ & $10.50 \pm 2.51$ & $<0.001$ \\
\hline Day (0900-2100 h) & $10.29 \pm 3.25$ & $10.62 \pm 3.33$ & $10.66 \pm 3.23$ & 0.008 \\
\hline Night $(0100-0600 \mathrm{~h})$ & $8.84 \pm 3.34$ & $9.40 \pm 3.29$ & $10.20 \pm 3.76$ & $<0.001$ \\
\hline$A R V_{D B P}(m m H g)$ & $6.85 \pm 1.72$ & $7.02 \pm 1.80$ & $7.25 \pm 2.01$ & $<0.001$ \\
\hline Day (0900-2100 h) & $7.13 \pm 2.61$ & $7.23 \pm 2.72$ & $7.34 \pm 2.79$ & 0.069 \\
\hline Night $(0100-0600 \mathrm{~h})$ & $6.46 \pm 2.63$ & $6.78 \pm 2.91$ & $7.13 \pm 3.13$ & $<0.001$ \\
\hline 7-day home BPV & $(n=1270)$ & $(n=337)$ & $(n=652)$ & \\
\hline $\mathrm{SD}_{\mathrm{SBP}}(\mathrm{mmHg})$ & $8.76 \pm 3.57$ & $9.37 \pm 3.40$ & $10.43 \pm 4.39$ & $<0.001$ \\
\hline $\mathrm{SD}_{\mathrm{DBP}}(\mathrm{mmHg})$ & $5.55 \pm 2.78$ & $5.89 \pm 2.47$ & $6.49 \pm 3.67$ & $<0.001$ \\
\hline
\end{tabular}

Data are presented as mean \pm SD. ANOVA, analysis of variance; ARV, average real variability; NGM, normal glucose metabolism; T2DM, type 2 diabetes mellitus.

${ }^{a} P$ (trend) for comparing linear trends across participants with normal glucose metabolism, prediabetes and T2DM were calculated with one-way ANOVA.

TABLE 3. Associations between glucose metabolism status and within-visit, 24-h and 7-day blood pressure variability

\begin{tabular}{|c|c|c|c|}
\hline & $\begin{array}{l}\text { NGM (ref) } \\
\beta(95 \% \mathrm{Cl})\end{array}$ & $\begin{array}{c}\text { Prediabetes } \\
\beta(95 \% \mathrm{Cl})\end{array}$ & $\begin{array}{c}\text { T2DM } \\
\beta(95 \% \mathrm{Cl})\end{array}$ \\
\hline \multicolumn{4}{|c|}{ Within-visit BPV } \\
\hline Model 1 & - & $0.37(0.08-0.66)$ & $0.26(0.01-0.50)$ \\
\hline Model 2 & - & $0.26(-0.03$ to 0.54$)$ & $0.05(-0.20$ to 0.29$)$ \\
\hline Model 3 & - & $0.26(-0.03$ to 0.55$)$ & $0.04(-0.21$ to 0.28$)$ \\
\hline Model 4 & - & $0.36(0.07-0.66)$ & $0.23(-0.07$ to 0.53$)$ \\
\hline Model 5 & - & $0.35(0.06-0.65)$ & $0.26(-0.04$ to 0.56$)$ \\
\hline \multicolumn{4}{|c|}{$\mathrm{SD}_{\mathrm{DBP}}(\mathrm{mmHg})$} \\
\hline Model 1 & - & $0.09(-0.09$ to 0.26$)$ & $0.10(-0.05$ to 0.26$)$ \\
\hline Model 2 & - & $0.04(-0.14$ to 0.21$)$ & $0.07(-0.07$ to 0.21$)$ \\
\hline Model 3 & - & $0.04(-0.14$ to 0.21$)$ & $0.04(-0.09$ to 0.20$)$ \\
\hline Model 4 & - & $0.07(-0.11$ to 0.25$)$ & $0.14(-0.04$ to 0.32$)$ \\
\hline Model 5 & - & $0.05(-0.13$ to 0.23$)$ & $0.10(-0.08$ to 0.28$)$ \\
\hline \multicolumn{4}{|l|}{ 24-h BPV } \\
\hline \multicolumn{4}{|c|}{$\mathrm{ARV}_{\mathrm{SBP}}(\mathrm{mmHg})$} \\
\hline Model 1 & - & $0.42(0.15-0.68)$ & $0.68(0.46-0.90)$ \\
\hline Model 2 & - & $0.24(-0.01$ to 0.49$)$ & $0.54(0.33-0.75)$ \\
\hline Model 3 & - & $0.23(-0.02$ to 0.48$)$ & $0.50(0.28-0.71)$ \\
\hline Model 4 & - & $0.03(-0.22$ to 0.28$)$ & $0.15(-0.10$ to 0.40$)$ \\
\hline Model 5 & - & $0.02(-0.23$ to 0.28$)$ & $0.14(-0.11$ to 0.39$)$ \\
\hline \multicolumn{4}{|c|}{$A R V_{D B P}(m m H g)$} \\
\hline Model 1 & - & $0.12(-0.08$ to 0.32$)$ & $0.36(0.19-0.53)$ \\
\hline Model 2 & - & $0.07(-0.13$ to 0.27$)$ & $0.42(0.25-0.58)$ \\
\hline Model 3 & - & $0.07(-0.13$ to 0.26$)$ & $0.38(0.21-0.55)$ \\
\hline Model 4 & - & $-0.09(-0.29$ to 0.11$)$ & $0.07(-0.13$ to 0.27$)$ \\
\hline Model 5 & - & $-0.10(-0.30$ to 0.10$)$ & $0.06(-0.15$ to 0.26$)$ \\
\hline \multicolumn{4}{|c|}{ 7-day home BPV } \\
\hline \multicolumn{4}{|c|}{$\mathrm{SD}_{\mathrm{SBP}}(\mathrm{mmHg})$} \\
\hline Model 1 & - & $0.41(-0.05$ to 0.87$)$ & $1.42(1.04-1.80)$ \\
\hline Model 2 & - & $0.08(-0.35$ to 0.51$)$ & $0.68(0.32-1.04)$ \\
\hline Model 3 & - & $0.06(-0.37$ to 0.49$)$ & $0.69(0.32-1.06)$ \\
\hline Model 4 & - & $0.13(-0.31$ to 0.57$)$ & $0.79(0.35-1.22)$ \\
\hline Model 5 & - & $0.06(-0.37$ to 0.50$)$ & $0.76(0.32-1.19)$ \\
\hline \multicolumn{4}{|c|}{$\mathrm{SD}_{\mathrm{DBP}}(\mathrm{mmHg})$} \\
\hline Model 1 & - & $0.29(-0.08$ to 0.66$)$ & $0.87(0.57-1.17)$ \\
\hline Model 2 & - & $0.19(-0.16$ to 0.55$)$ & $0.84(0.55-1.13)$ \\
\hline Model 3 & - & $0.18(-0.18$ to 0.54$)$ & $0.83(0.53-1.13)$ \\
\hline Model 4 & - & $0.17(-0.19$ to 0.53$)$ & $0.69(0.33-1.04)$ \\
\hline Model 5 & - & $0.12(-0.24$ to 0.48$)$ & $0.65(0.29-1.01)$ \\
\hline
\end{tabular}

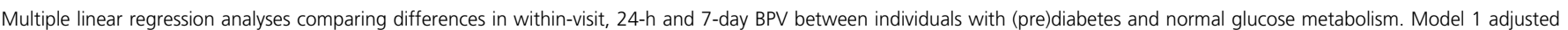

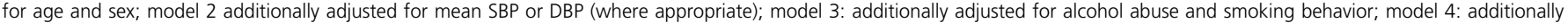
adjusted for BMI, prior CVD, HDL, LDL, lipid-lowering medication and eGFR; model 5: additionally adjusted for classes of antihypertensive medication. Bold values denote statistically

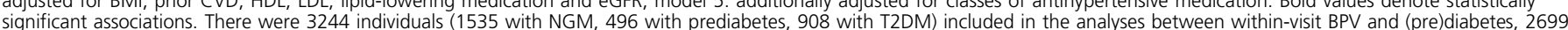
significant associations. There were 3244 individuals (1535 with NGM, 496 with prediabetes, 908 with T2DM) included in the analyses between within-visit BPV and (pre)diabetes,
individuals ( 1535 with NGM, 411 with prediabetes, 753 with T2DM) included in the analyses between 24-h BPV and (pre)diabetes, 2259 individuals (1270 with NGM, 337 with prediabetes, 625 with T2DM) included in the analyses between 7-day BPV and (pre)diabetes. ARV, average real variability; CI, confidence interval; NGM, normal glucose metabolism; T2DM, type 2 diabetes mellitus. 
Both prediabetes and T2DM were not statistically significantly associated with within-visit diastolic BPV as compared with NGM (Table 3, upper panel).

\section{Twenty-four-hour blood pressure variability}

After adjustment for the covariates of the models 1-3, T2DM, but not prediabetes, was associated with greater 24-h systolic BPV as compared with NGM $[0.50 \mathrm{mmHg}$ $(0.28-0.71)]$. These results were attenuated and not statistically significant after further adjustment for the covariates of model 4 [0.15 mmHg $(-0.13$ to 0.27$)]$ or model 5 [0.14 mmHg ( -0.11 to 0.39$)]$ (Table 3, middle panel). The attenuating effect seen between models 3 and 4 was mainly caused by adding BMI in model 4 .

After adjustment for the covariates of the models 1-3, only T2DM, but not prediabetes, was associated with greater 24-h diastolic BPV as compared with NGM $[0.38 \mathrm{mmHg}$ (0.21-0.55)]. These results were attenuated and not statistically significant after further adjustment for the covariates of model 4 [0.07 mmHg $(-0.13$ to 0.27$)]$ or model 5 [0.06 mmHg ( -0.15 to 0.26)] (Table 3, middle panel). Again, the attenuating effect seen between models 3 and 4 was mainly caused by adding BMI in model 4 .

If we analyzed daytime and night-time BPV separately, only T2DM was associated with greater nocturnal systolic BPV after adjustment for the covariates of the models $1-5$ as compared with NGM [0.42 mmHg (0.050.80)] (Table 4).

\section{Seven-day blood pressure variability}

After adjustment for the covariates of the models 1-3, only T2DM, but not prediabetes, was associated with greater 7-day systolic BPV as compared with NGM $[0.69 \mathrm{mmHg}$ (0.32-1.06)]. This association became somewhat stronger after further adjustment for the covariates of model 4 [0.79 mmHg (0.35-1.22)] and model 5 [0.76 $\mathrm{mmHg}(0.32-$ 1.19)].

After adjustment for the covariates of the models 1-3, only T2DM, but not prediabetes, was associated with greater 7-day diastolic BPV as compared with NGM [0.83 mmHg (0.53-1.13)]. This association was somewhat attenuated after further adjustment for the covariates of model 5 [0.65 mmHg (0.29-1.01)].

\section{Additional analyses}

After additional adjustment for waist circumference (instead of BMI), HR, the actual number of BP measurements and physical activity, the results did not materially change (Supplemental material Tables S3-S6, http://links.lww. com/HJH/A838).

If we repeated the analyses for within-visit BPV with coefficient of variation and the difference between maximum and minimum BP, and for 24-h BPV with weighted SD and weighted coefficient of variation, and for 7-day BPV with average real variability and coefficient of variation, the results were not materially changed (Supplemental material Tables S7-S9, http://links.lww.com/HJH/A838).

\section{TABLE 4. Associations between glucose metabolism status and blood pressure variability during daytime and night-time as estimated} from ambulatory blood pressure measurements

\begin{tabular}{|c|c|c|c|}
\hline & $\begin{array}{l}\text { NGM (ref) } \\
\beta(95 \% \mathrm{Cl})\end{array}$ & $\begin{array}{c}\text { Prediabetes } \\
\beta(95 \% \mathrm{CI})\end{array}$ & $\begin{array}{c}\text { T2DM } \\
\beta(95 \% \mathrm{Cl})\end{array}$ \\
\hline \multicolumn{4}{|c|}{ 24-h BPV, day only } \\
\hline Model 1 & - & $0.28(-0.07$ to 0.63$)$ & $0.44(0.15-0.73)$ \\
\hline Model 2 & - & $0.12(-0.22$ to 0.45$)$ & $0.36(0.08-0.64)$ \\
\hline Model 3 & - & $0.10(-0.24$ to 0.44$)$ & $0.29(0.01-0.58)$ \\
\hline Model 4 & - & $-0.10(-0.44$ to 0.24$)$ & $-0.08(-0.42$ to 0.26$)$ \\
\hline Model 5 & - & $-0.09(-0.43$ to 0.25$)$ & $-0.06(-0.41$ to 0.29$)$ \\
\hline \multicolumn{4}{|c|}{$A R V_{D B P}(\mathrm{mmHg})$} \\
\hline Model 1 & - & $0.12(-0.17$ to 0.42$)$ & $0.28(0.04-0.53)$ \\
\hline Model 2 & - & $0.06(-0.23$ to 0.35$)$ & $0.39(0.14-0.63)$ \\
\hline Model 3 & - & $0.05(-0.24$ to 0.34$)$ & $0.32(0.07-0.57)$ \\
\hline Model 4 & - & $-0.14(-0.43$ to 0.16$)$ & $-0.04(-0.34$ to 0.25$)$ \\
\hline Model 5 & - & $-0.13(-0.43$ to 0.16$)$ & $-0.06(-0.36$ to 0.24$)$ \\
\hline \multicolumn{4}{|c|}{ 24-h BPV, night only } \\
\hline \multicolumn{4}{|c|}{$A R V_{\text {SBP }}(\mathrm{mmHg})$} \\
\hline Model 1 & - & $0.36(-0.01$ to 0.73$)$ & $1.07(0.76-1.38)$ \\
\hline Model 2 & - & $0.27(-0.10$ to 0.64$)$ & $0.82(0.51-1.13)$ \\
\hline Model 3 & - & $0.27(-0.10$ to 0.64$)$ & $0.85(0.54-1.17)$ \\
\hline Model 4 & - & $0.01(-0.36$ to 0.38$)$ & $0.42(0.04-0.79)$ \\
\hline Model 5 & - & $-0.01(-0.38$ to 0.36$)$ & $0.42(0.05-0.80)$ \\
\hline \multicolumn{4}{|c|}{$A R V_{D B P}(\mathrm{mmHg})$} \\
\hline Model 1 & - & $0.20(-0.11$ to 0.50$)$ & $0.44(0.18-0.69)$ \\
\hline Model 2 & - & $0.15(-0.16$ to 0.45$)$ & $0.42(0.16-0.67)$ \\
\hline Model 3 & - & $0.14(-0.17$ to 0.44$)$ & $0.40(0.14-0.66)$ \\
\hline Model 4 & - & $-0.07(-0.38$ to 0.24$)$ & $-0.03(-0.34$ to 0.28$)$ \\
\hline Model 5 & - & $-0.09(-0.41$ to 0.22$)$ & $-0.07(-0.38$ to 0.25$)$ \\
\hline
\end{tabular}

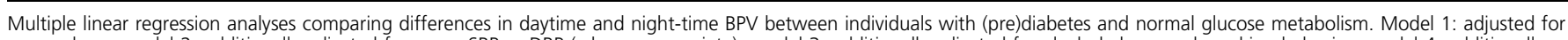
age and sex; model 2: additionally adjusted for mean SBP or DBP (where appropriate); model 3: additionally adjusted for alcohol abuse and smoking behavior; model 4: additionally

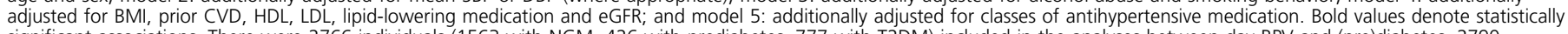
significant associations. There were 2766 individuals (1563 with NGM, 426 with prediabetes, 777 with T2DM) included in the analyses between day BPV and (pre)diabetes, 2790 individuals (1586 with NGM, 424 with prediabetes, 780 with T2DM) included in the analyses between nocturnal BPV and (pre)diabetes. ARV, average real variability; Cl, confidence interval; NGM, normal glucose metabolism; T2DM, type 2 diabetes mellitus. 
Sex was an effect modifier in some of the associations between glucose metabolism status and BPV, but not all: the associations between prediabetes, and systolic withinvisit and 7-day BPV were weaker in women, whereas the associations between prediabetes and T2DM, and systolic 24-h BPV were stronger in women. For both day and night, the association between T2DM and systolic BPV was stronger in women (details presented in Supplemental material Table S10, http://links.lww.com/HJH/A838).

Further analyses into antihypertensive medication and class effects on BPV [10] were hampered by a severe loss of statistical power (data not shown).

\section{DISGUSSION}

The current study had two main findings. First, the average systolic/diastolic values of within-visit, 24-h and 7-day BPV in our study population were substantial: 4.8/2.6, 10.5/7.3 and $10.4 / 6.5 \mathrm{mmHg}$, respectively, in individuals with T2DM, and 5.0/2.6, 10.3/7.0 and 9.4/5.9 mmHg, respectively, in individuals with prediabetes. Second, these values were, after adjustment for potential confounders, slightly larger than those in individuals with NGM. Specifically, T2DM was associated with significantly greater nocturnal systolic BPV and greater 7-day systolic and diastolic BPV, whereas prediabetes was associated with significantly greater within-visit systolic BPV only. According to previous literature, the slightly greater very short-term to mid-term BPV seen in (pre)diabetes corresponds to a relatively modest $\sim 4 \%$ increased risk of cardiovascular events over an observation period of 5-7 years (e.g. an increase from 9.0 to $9.4 \%)[23,24]$, on the assumption that there is no interaction (synergy) between (pre)diabetes and very short-term to mid-term BPV. However, the average very short-term to mid-term BPV values we observed are in agreement with previous studies, which have shown that very short-term to mid-term BPV plays an important role in incident CVD $[4,23,24]$. Thus, these findings suggest that very short-term to mid-term BPV may, at most, explain a small part of the increased CVD risk seen in (pre)diabetes, but it does not detract from the fact that, regardless of the presence of (pre)diabetes, very short-term to mid-term BPV is substantial and important.

Previous studies on BPV in (pre)diabetes have not yielded consistent results. Two large Asian population-based studies did not present numerical values of differences in BPV values between individuals with (pre)diabetes and NGM [8,9], and one study [8] investigated associations with new-onset diabetes only. In addition, two relatively small studies [5,6] showed large differences in BPV, up to $3.7 \mathrm{mmHg}$, between individuals with (pre)diabetes and NGM, but did not adjust for potential confounders, such as age, mean BPs or the use of various classes of antihypertensive medication [5,6]. Hence, the results of the current study, in a population-based cohort enriched with individuals with T2DM, add to the existing literature by presenting accurate (differences in) BPV estimates, as we adhered to international guidelines on BP measurements $[15,16,18]$ and were able to adjust for a large number of potential confounders.

The slightly greater very short-term to mid-term BPV in individuals with (pre)diabetes may be related to several factors, such as impaired baroreflex sensitivity caused by arterial carotid stiffening [25-27], and overactivity of the sympathetic nervous system caused by obesity [28] and/or (undiagnosed) sleep disordered breathing [29-31]. Further study is required to test these hypotheses.

Previous studies have suggested that in the presence of T2DM, CVD risk increases more in women as compared with men [32]. Our results, however, showed no clear pattern with regard to greater in BPV in women with (pre)diabetes, and these findings may represent the play of chance.

A major strength of the current report is the precise measurement of BPV estimates. In addition, OGTT-based classification of glucose metabolism status and the oversampling of individuals with T2DM enabled sufficient statistical power to accurately estimate BPV in (pre)diabetes. Also, we were able to adjust for an extensive range of covariates, including the use of various classes of antihypertensive medication. In fact, this may have led to some overadjustment, as, for instance, decreased renal function may lie in the causal pathway between (pre)diabetes and greater BPV. Consequently, we may, to some extent, have underestimated differences in BPV between individuals with (pre)diabetes and NGM [33]. Therefore, the true association will lie between model 3 , in which only true confounders were added, and model 4 . Even so, however, model 3 still shows that differences in BPV between individuals with (pre)diabetes and NGM are relatively modest. On the other hand, it should be emphasized that these modest differences were obtained in a study population that was well treated with regard to BP. Importantly, the latter implies that BPV-associated risk of CVD in (pre)diabetes can be reduced to approximately the same level as in individuals with NGM.

The current study had some further limitations. First, in light of the above, the generalizability of our results may be limited to white populations and those who had access to high-quality hypertension care. Second, due to the crosssectional design of the study, any causal inference should be made with caution. Third, data on long-term BPV, that is visitto-visit BPV, were unavailable. Visit-to-visit BPV has been strongly associated with incident CVD [34], and is a distinct type of BPV, as its underlying mechanisms are different from those of other types of BPV and include aging and seasonal climatic changes [35]. Hence, long-term BPV is not interchangeable with (very) short-term BPV [4,36].

In conclusion, individuals with (pre)diabetes have a slightly greater very short-term to mid-term BPV than those with NGM, which may explain a small part of the increased CVD risk seen in (pre)diabetes. Despite these small differences, very short-term to mid-term BPV remains substantial and important in individuals with and without (pre)diabetes. The results of the current study imply that greater very short-term to mid-term BPV may need to be considered as an important, treatable risk factor for CVD, regardless of glucose metabolism status. In addition, these results may also imply that when hypertension is well controlled, as is the case in our study population, the BPV-associated risk on CVD in (pre)diabetes may be reduced to approximately the same level as in individuals with NGM. Future research should explore whether the same applies to long-term BPV, that is visit-to-visit BPV, in individuals with and without (pre)diabetes. 


\section{AGKNOWLEDGEMENTS}

Previous presentations: The work has not been presented previously.

Sources of funding: This study was supported by the European Regional Development Fund via OP-Zuid, the Province of Limburg, the Dutch Ministry of Economic Affairs (grant 310.041), Stichting De Weijerhorst (Maastricht, The Netherlands), the Pearl String Initiative Diabetes (Amsterdam, The Netherlands), the Cardiovascular Center (CVC, Maastricht, The Netherlands), CARIM School for Cardiovascular Diseases (Maastricht, the Netherlands), CAPHRI School for Public Health and Primary Care (Maastricht, The Netherlands), NUTRIM School for Nutrition and Translational Research in Metabolism (Maastricht, The Netherlands), Stichting Annadal (Maastricht, the Netherlands), Health Foundation Limburg (Maastricht, The Netherlands) and by unrestricted grants from Janssen-Cilag B.V. (Tilburg, The Netherlands), Novo Nordisk Farma B.V. (Alphen aan den Rijn, The Netherlands) and Sanofi-Aventis Netherlands B.V. (Gouda, The Netherlands).

\section{Conflicts of interest}

There are no conflicts of interest.

\section{REFERENGES}

1. Beckman JA, Creager MA, Libby P. Diabetes and atherosclerosis: epidemiology, pathophysiology, and management. JAMA 2002; 287:2570-2581.

2. Huang Y, Cai X, Chen P, Mai W, Tang H, Huang Y, et al. Associations of prediabetes with all-cause and cardiovascular mortality: a meta-analysis. Ann Med 2014; 46:684-692.

3. NCD Risk Factor Collaboration (NCD-RisC). Worldwide trends in diabetes since 1980: a pooled analysis of 751 population-based studies with 4.4 million participants. Lancet 2016; 387:1513-1530.

4. Rothwell PM, Howard SC, Dolan E, O'Brien E, Dobson JE, Dahlof B, et al. Prognostic significance of visit-to-visit variability, maximum systolic blood pressure, and episodic hypertension. Lancet 2010; 375:895-905.

5. Ozawa M, Tamura K, Iwatsubo K, Matsushita K, Sakai M, TsurumiIkeya Y, et al. Ambulatory blood pressure variability is increased in diabetic hypertensives. Clin Exp Hypertens 2008; 30:213-224.

6. Mokhtar RH, Ayob A, Mohd Noor N. Blood pressure variability in patients with diabetes mellitus. Asian Cardiovasc Thorac Ann 2010; 18:344-348.

7. Michel-Chavez A, Estanol B, Gien-Lopez JA, Robles-Cabrera A, Huitrado-Duarte ME, Moreno-Morales R, et al. Heart rate and systolic blood pressure variability on recently diagnosed diabetics. Arq Bras Cardiol 2015; 105:276-284.

8. Yano Y, Fujimoto S, Kramer H, Sato Y, Konta T, Iseki K, et al. Long-term blood pressure variability, new-onset diabetes mellitus, and new-onset chronic kidney disease in the Japanese general population. Hypertension 2015; 66:30-36.

9. Okada R, Yasuda Y, Tsushita K, Wakai K, Hamajima N, Matsuo S. Within-visit blood pressure variability is associated with prediabetes and diabetes. Sci Rep 2015; 5:7964.

10. Webb AJ, Fischer U, Mehta Z, Rothwell PM. Effects of antihypertensivedrug class on interindividual variation in blood pressure and risk of stroke: a systematic review and meta-analysis. Lancet 2010; 375:906-915.

11. Kronish IM, Lynch AI, Oparil S, Whittle J, Davis BR, Simpson LM, et al. The association between antihypertensive medication nonadherence and visit-to-visit variability of blood pressure: findings from the antihypertensive and lipid-lowering treatment to prevent heart attack trial. Hypertension 2016; 68:39-45.

12. Epstein M, Sowers JR. Diabetes mellitus and hypertension. Hypertension 1992; 19:403-418.
13. Parati G, Ochoa JE, Salvi P, Lombardi C, Bilo G. Prognostic value of blood pressure variability and average blood pressure levels in patients with hypertension and diabetes. Diabetes Care 2013; 36 (Suppl 2):S312-S324.

14. Schram MT, Sep SJ, van der Kallen CJ, Dagnelie PC, Koster A, Schaper $\mathrm{N}$, et al. The Maastricht Study: an extensive phenotyping study on determinants of type 2 diabetes, its complications and its comorbidities. Eur J Epidemiol 2014; 29:439-451.

15. Pickering TG, Hall JE, Appel LJ, Falkner BE, Graves J, Hill MN, et al. Recommendations for blood pressure measurement in humans and experimental animals: Part 1: blood pressure measurement in humans: a statement for professionals from the Subcommittee of Professional and Public Education of the American Heart Association Council on High Blood Pressure Research. Hypertension 2005; 45:142-161.

16. O'Brien E, Parati G, Stergiou G, Asmar R, Beilin L, Bilo G, et al. European Society of Hypertension position paper on ambulatory blood pressure monitoring. J Hypertens 2013; 31:1731-1768.

17. Mena L, Pintos S, Queipo NV, Aizpurua JA, Maestre G, Sulbaran T. A reliable index for the prognostic significance of blood pressure variability. J Hypertens 2005; 23:505-511.

18. Parati G, Stergiou GS, Asmar R, Bilo G, de Leeuw P, Imai Y, et al. European Society of Hypertension practice guidelines for home blood pressure monitoring. J Hum Hypertens 2010; 24:779-785.

19. World Health Organization. Definition and diagnosis of diabetes mellitus and intermediate byperglycemia: report of a WHO/IDF consultation. Geneva, Switzerland: World Health Organization; 2006.

20. Inker LA, Schmid CH, Tighiouart H, Eckfeldt JH, Feldman HI, Greene T, et al. Estimating glomerular filtration rate from serum creatinine and cystatin C. N Engl J Med 2012; 367:20-29.

21. Bilo G, Giglio A, Styczkiewicz K, Caldara G, Maronati A, KaweckaJaszcz K, et al. A new method for assessing 24-h blood pressure variability after excluding the contribution of nocturnal blood pressure fall. J Hypertens 2007; 25:2058-2066.

22. Rothman KJ. No adjustments are needed for multiple comparisons. Epidemiology 1990; 1:43-46.

23. Palatini P, Reboldi G, Beilin LJ, Casiglia E, Eguchi K, Imai Y, et al. Added predictive value of night-time blood pressure variability for cardiovascular events and mortality: the Ambulatory Blood Pressure-International Study. Hypertension 2014; 64:487-493.

24. Johansson JK, Niiranen TJ, Puukka PJ, Jula AM. Prognostic value of the variability in home-measured blood pressure and heart rate: the FinnHome Study. Hypertension 2012; 59:212-218.

25. Mattace-Raso FU, van den Meiracker AH, Bos WJ, van der Cammen TJ, Westerhof BE, Elias-Smale S, et al. Arterial stiffness, cardiovagal baroreflex sensitivity and postural blood pressure changes in older adults: the Rotterdam Study. J Hypertens 2007; 25:1421-1426.

26. Okada Y, Galbreath MM, Shibata S, Jarvis SS, VanGundy TB, Meier RL, et al. Relationship between sympathetic baroreflex sensitivity and arterial stiffness in elderly men and women. Hypertension 2012; 59:98-104.

27. Liu YP, Gu YM, Thijs L, Asayama K, Jin Y, Jacobs L, et al. Do level and variability of systolic blood pressure predict arterial properties or vice versa? J Hum Hypertens 2014; 28:316-322.

28. Hall JE. The kidney, hypertension, and obesity. Hypertension 2003; 41 (3 Pt 2):625-633.

29. Narkiewicz K, van de Borne PJ, Cooley RL, Dyken ME, Somers VK. Sympathetic activity in obese subjects with and without obstructive sleep apnea. Circulation 1998; 98:772-776.

30. Wolk R, Shamsuzzaman AS, Somers VK. Obesity, sleep apnea, and hypertension. Hypertension 2003; 42:1067-1074.

31. Grassi G, Facchini A, Trevano FQ, Dell'Oro R, Arenare F, Tana F, et al. Obstructive sleep apnea-dependent and -independent adrenergic activation in obesity. Hypertension 2005; 46:321-325.

32. Regensteiner JG, Golden S, Huebschmann AG, Barrett-Connor E, Chang AY, Chyun D, et al. Sex differences in the cardiovascular consequences of diabetes mellitus: a scientific statement from the American Heart Association. Circulation 2015; 132:2424-2447.

33. Schisterman EF, Cole SR, Platt RW. Overadjustment bias and unnecessary adjustment in epidemiologic studies. Epidemiology 2009; 20:488-495.

34. Diaz KM, Tanner RM, Falzon L, Levitan EB, Reynolds K, Shimbo D, et al. Visit-to-visit variability of blood pressure and cardiovascular disease and all-cause mortality: a systematic review and meta-analysis. Hypertension 2014; 64:965-982. 
35. Parati G, Ochoa JE, Lombardi C, Bilo G. Blood pressure variability: assessment, predictive value, and potential as a therapeutic target. Curr Hypertens Rep 2015; 17:537.

\section{Reviewer's Summary Evaluation}

\section{Reviewer 2}

The study examined short-term and long-term measures of $\mathrm{BP}$ variability in over 3000 normal patients and those with prediabetes and diabetes. The strength of the analysis employed is the multiple linear regression with adjustment for potential confounders and included five different models. The main findings were that greater nocturnal systolic
36. Muntner P, Shimbo D, Diaz KM, Newman J, Sloan RP, Schwartz JE. Low correlation between visit-to-visit variability and 24-h variability of blood pressure. Hypertens Res 2013; 36:940-946.

blood pressure variability and greatest seven-day systolic variability and diastolic variability in patients with diabetes compared to normal subjects. By contrast, prediabetic's were associated with a greater within visit systolic blood pressure variability only. It must be said that differences between the three groups were relatively small and whether this is enough to predict increased cardiovascular risk would need to be determined in the long-term. 